\title{
TRABAJOS GANADORES PRESENTADOS EN EL XXX CONGRESO NACIONAL DE OBSTETRICIA Y GINECOLOGÍA REALIZADO DEL 25 AL 28 DE MAYO DE 2016 EN CALI (COLOMBIA)
}

\section{Prize-winning work presented at the 30th National Obstetrics and Gynecology Congress held between the 25th and 28th of May 2016 in Cali (Colombia)}

\section{CATEGORÍA: PRESENTACIÓN ORAL}

\section{CONSEJERÍA GENÉTICA Y \\ REPRODUCTIVA EN PORTADORES \\ DE PREMUTACIÓN EN UN \\ CONGLOMERADO GEOGRÁFICO DE \\ SÍNDROME X FRÁGIL}

\section{Wilmar Saldarriaga-Gil, José Vicente \\ Forero-Forero, Andrés Fandiño-Losada, Julián Ramírez-Cheyne, Julieth Tatiana Rodríguez-Forero, de la Universidad del Valle y Flora Tassone de la Universidad de California. wilmar.saldarriaga@correounivalle.edu.co}

Introducción: Ricaurte es un corregimiento vallecaucano en el que se ha documentado un conglomerado geográfico de síndrome X frágil (SXF), 1 en 38 hombres y 1 en 100 mujeres.

El SXF es una enfermedad genética causada por la expansión inestable de la tripleta CGG en el gen FMR1; existen cuatro rangos de cantidad de tripletas: hasta 44, normal; 45-55, zona gris, que se puede expandir heredando el alelo en premutación; 55-200, premutación, y puede presentar síndromes asociados como temblor-ataxia (STAFX) y falla ovárica primaria (FOPFX), además de expandir heredando el alelo con mutación completa; y más de 200 repeticiones, mutación completa (MC) la cual causa el SXF con discapacidad intelectual, facies particulares y trastornos del lenguaje.

La consejería genética, los métodos anticonceptivos apropiados y embarazos planeados, idealmente con diagnóstico prenatal, cobran trascendental importancia para disminuir el número de casos nuevos.

El objetivo de este trabajo fue determinar la prevalencia de portadores de la premutación de SXF en Ricaurte y realizar consejería genética, médica y reproductiva. Además, cuantificar la frecuencia de FOPFX y STAFX.

Materiales y métodos: estudio transversal de genética poblacional. Población: todos los habitantes de Ricaurte (1.134) que firmaran consentimiento o por su acudiente. Se abordó la población tocando puerta a puerta en cada casa. Se tomaron gotas de sangre recolectadas en papel filtro a las cuales se les realizó prueba molecular tipo PCR. Construcción de heredogramas con software Progeny. Los análisis de prevalencia con el software Stata 14.

Resultados: se tomaron muestras de 412 mujeres y 360 hombres, encontrando con premutación 28 y 3 respectivamente. Prevalencia 1 de 23 mujeres y 1 de 120 hombres como portadores de la premutación. 
Se realizó consejería genética específica informando a las mujeres con premutación que tienen un riesgo de $50 \%$ de tener hijos afectados. Se indicaron métodos anticonceptivos pertinentes a cada una de las portadoras.

$\mathrm{Al}$ momento de la intervención 17 mujeres no tenían futuro obstétrico; de estas, 3 eran G0P0 y una de ellas tuvo histerectomía a los 35 años.

En 6 ligadura de trompas.

En 5 métodos anticonceptivos temporales: anticonceptivos orales (1) y dispositivo intrauterino (4).

En una se hizo orientación preconcepcional.

Conclusión: la consejería genética y el uso de métodos anticonceptivos individualizados en portadores de la premutación del gen FMR1 producirá un impacto notorio disminuyendo el número de nacimientos de afectados por el SXF. Se aspira a que el conglomerado geográfico de SXF desaparezca de Ricaurte. Este trabajo muestra una intervención en salud pública a través de prevención secundaria que integra pruebas moleculares y consejería genética a la ginecoobstetricia.

Palabras clave: síndrome $\mathrm{X}$ frágil, consejería genética, métodos anticonceptivos, premutación.

\section{CATEGORÍA: PÓSTER}

\section{¿ES ÚTIL LA MEDICIÓN DEL COCIENTE} SFLT-1 / PIGF (SOLUBLE FMS-LIKE TYROSINE KINASE-1 / PLACENTAL GROWTH FACTOR) CALCULADO EN EL PRIMER TRIMESTRE COMO PREDICTOR DE PREECLAMPSIA?

Giuliana Puccini, Juan Carlos Mendoza, Jeannette Cubillos, Hernando Ruiz, Janeth Barrera, Asociados en Reproducción Humana, Bogotá, Colombia.giupusa@gmail.com

Introducción: la preeclampsia (hipertensión arterial con presión diastólica $\geq 90 \mathrm{~mm} / \mathrm{Hg}$ después de la semana 20 de gestación), afecta 1/20 embarazos y produce $1 / 4$ muertes maternas en el mundo, cifras que pueden ser aún más altas en nuestro país debido al gran número de partos que aún se atienden en condiciones subóptimas en la población rural. Tanto la disminución del factor de crecimiento placentario (PlGF) como el aumento del factor tirosinkinasa -1 soluble tipo fms (sFlt-1) han sido evaluados previamente como factores predictores de preeclampsia de manera independiente. En enero de 2016, en NEJM, Zeisler et al. publicaron el estudio "Prognosis", en el cual se demuestra la utilidad de realizar un cociente entre ambas pruebas en lugar de usarlas de manera independiente, en pacientes con embarazo único, con sospecha de preeclampsia entre las $24 \mathrm{y}$ las 36 semanas. Así, un cociente sFlt-1/PlGF $\leq 38$ descarta la aparición de preeclampsia en la semana siguiente con un VPN del 99,3\%, mientras que uno $\geq 38$ predice la aparición de preeclampsia en las cuatro semanas siguientes con un VPP del 36,7\%.

El objetivo de este trabajo es evaluar el desempeño del cociente sFlt-1/PLGF como predictor de preeclampsia en el primer trimestre, en un grupo de pacientes con embarazo único.

Materiales y métodos: estudio descriptivo realizado entre enero de 2014 y diciembre de 2015; se estudiaron 38 pacientes, con edad promedio de 35,4 +/- 4,1 años, con embarazo único; se les realizó sFlt-1 y PlGF (Roche Diagnostics) junto con los marcadores bioquímicos del tamizaje genético de primer trimestre, se les calculó el cociente sFlt-1/ PlGF (negativo: $<38$, positivo $>38$ ) y se analizó el resultado perinatal (edad gestacional al parto, preeclampsia y restricción del crecimiento intrauterino - RCIU).

Resultados: en nuestra población, 5 partos pretérmino (1 extremo: 26 semanas y 4 tardíos: 3436 semanas). Solo 3, incluido el extremo, tuvieron cociente positivo; de 5 pacientes con preeclampsia leve, solo 3 (60\%) tuvieron cociente $>38$, y solo una, con valor de 52, tuvo RCIU. De las otras 33 pacientes a término 6 tuvieron preeclampsia leve (60\% cociente positivo). Adicionalmente, se encon- 
traron 6 casos de RCIU aislado con pesos $<2500$ (100\% cociente > 38). Sin embargo, 12/19 (63\%) pacientes tuvieron cociente $>38$ sin ningún desenlace adverso.

Conclusiones: en la población estudiada no se evidenció una correlación tan fuerte del índice sFlt-1/ PlGF con la ausencia o presencia de preeclampsia. Esto puede deberse a que en el estudio original, la predicción se da aproximadamente 5 semanas antes de la aparición de la preeclampsia, y todas nuestras muestras fueron tomadas en el primer trimestre. Sin embargo, sí encontramos correlación del 100\% con los casos de RCIU. Llama la atención que el 63\% tenga cociente positivo con resultado favorable.

Palabras clave: preeclampsia, sFlt-1/PlGF, RCIU.

\section{CATEGORÍA: VIDEO}

TRAQUELECTOMÍA RADICAL Y

LINFADENECTOMÍA PÉLVICA POR

LAPAROSCOPIA

Indira Rosero Martínez, Carlos Díaz Reyes,

Luis René Pareja Franco, Clínica Nuestra Señora

de los Remedios, Cali, Colombia.

indi817@yahoo.es

Introducción: presentación en video del primer caso de traquelectomía radical y linfadenectomía pélvica por laparoscopia, en la ciudad de Cali (Colombia), como manejo conservador del cáncer de cérvix, en una paciente con adenocarcinoma de cérvix estadio FIGO IB1. Se estableció un protocolo de manejo intraoperatorio por etapas.
Materiales y métodos: paciente de 33 años (grávida 0 , para 0) con deseo genésico, con diagnóstico de adenocarcinoma infiltrante de endocervix estadio FIGO IB1, diagnosticado por conización cervical y confirmado por estudios de inmunohistoquímica, quien se programa a traquelectomía radical y linfadenectomía pélvica por laparoscopia.

A la paciente se le informó del procedimiento y se obtuvo el consentimiento informado detallado, al igual que el consentimiento para grabar y realizar el video.

La estrategia quirúrgica consistió en realizar la disección de los espacios anatómicos, y la sección radical de los ligamentos cardinales y uterosacros, con la preservación del nervio hipogástrico, y preservándose íntegramente la irrigación del cuerpo uterino.

Resultados: la cirugía se realizó satisfactoriamente, con una media de duración de 3 horas. El análisis histológico intraoperatorio de biopsia por congelación del cérvix fue negativo para lesión residual, al igual que los bordes externo y vértice del cono.

Reporte definitivo de patología negativo para lesión residual, bordes libres de lesión maligna.

Conclusiones: la traquelectomía radical por laparoscopia, incluida la sección de los ligamentos cardinales y uterosacros, permite conservar la irrigación del cuerpo uterino y facilita la traquelectomía por vía vaginal.

Es una técnica reproducible y aplicable para el manejo de esta patología, con disminución de la morbilidad asociada a este tipo de procedimientos con las técnicas convencionales.

Palabras clave: traquelectomía radical, laparoscopia, cáncer cervical. 